\title{
Letter to the Editor concerning "Anatomic relationship between the cervical sympathetic trunk and cervical fascia and its application in the anterolateral cervical spine surgical approach" by $M$. Chen et al. (Eur Spine J [2021] 30; 425-430)
}

\author{
Naci Balak ${ }^{1}$ iD \\ Received: 17 May 2021 / Accepted: 24 October 2021 / Published online: 1 November 2021 \\ ๑) The Author(s), under exclusive licence to Springer-Verlag GmbH Germany, part of Springer Nature 2021
}

To the Editor

Horner's syndrome can occur as a result of injury to the cervical sympathetic trunk (CST); it is a relatively common complication that causes both functional and cosmetic problems in cervical anterolateral approaches such as oblique corpectomy [1-3]. The article, which was recently published in Eur Spine J 30:425-430 by Chen et al. [3] demonstrates a surgical technique for securing the CST in cadavers and is therefore very valuable.

The authors suggest that the cervical sympathetic trunk can be preserved by dissection and retraction of the alar fascia during surgery. However, the layers of the deep cervical fascia are anatomically controversial [4], and many textbooks do not include the term 'alar fascia'. Generally, the deep fascia is defined as the prevertebral layer of cervical fasciae, and the alar fascia has been described as a loose and thin band connecting the carotid sheaths. Its presence as a separate layer has only been clearly demonstrated histologically [4]. Therefore, it may be difficult to dissect the alar fascia as a separate layer during actual surgery where there is, unlike in anatomical studies, a limited field of view. In fact, the technique of preparing an aponeurotic flap using the prevertebral fascia and placing it for protection by rolling over the CST has been previously reported without explicitly mentioning a separate alar fascia $[1,2]$.

The CST is usually located on the prevertebral fascia and behind the carotid sheath. Consequently, even if the alar fascia could be dissected as a separate layer during surgery, this thin cover may not provide safe enough protection for the

Naci Balak

naci.balak@gmail.com; drnacibalak@yahoo.com

1 Department of Neurosurgery, Göztepe Hospital, Istanbul Medeniyet University, Istanbul, Turkey
CST behind the carotid sheath. The report of Chen et al. [3] is one of very few studies to demonstrate the use of a fascial flap to protect the CST in anterolateral surgical interventions. Nevertheless, the aforementioned potential confusion around using the alar fascia as a protective flap needs to be clarified.

Funding The author has no personal, financial, or institutional interest in any of the drugs, materials, or devices described in this article.

\section{Declarations}

Conflict of interest The author declares that there is no conflict of interest.

Ethical approval The ethical issues for this study involving human subjects have been carefully considered in line with the Declaration of HELSINKI (1964).

\section{References}

1. Balak N, Baran O, Denli Yalvac ES, Esen Aydin A, Tanriover N (2019) Surgical technique for the protection of the cervical sympathetic trunk in anterolateral oblique corpectomy: a new cadaveric demonstration. J Clin Neurosci 63:267-271. https://doi.org/10. 1016/j.jocn.2019.01.019

2. George B, Bruneau M, Spetzler RF (2011) Pathology and surgery around the vertebral artery. Springer-Verlag, Paris

3. Chen M, Tang H, Shan J (2021) Anatomic relationship between the cervical sympathetic trunk and cervical fascia and its application in the anterolateral cervical spine surgical approach. Eur Spine J 30:425-430. https://doi.org/10.1007/s00586-020-06621-2

4. Gavid M, Dumollard JM, Habougit C, Lelonge Y, Bergandi F, Peoc'h M, Prades JM (2018) Anatomical and histological study of the deep neck fasciae: does the alar fascia exist? Surg Radiol Anat 40:917-922. https://doi.org/10.1007/s00276-018-1977-5

Publisher's Note Springer Nature remains neutral with regard to jurisdictional claims in published maps and institutional affiliations. 